\title{
Status differences in employee adjustment during organizational change
}

\author{
Angela J. Martin \\ School of Management, University of Tasmania, Hobart, Australia \\ Elizabeth S. Jones \\ School of Psychology, Griffith University, Brisbane, Australia, and \\ Victor J. Callan \\ School of Business, The University of Queensland, Brisbane, Australia
}

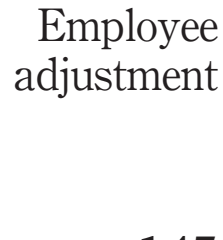

145

Received December 2004

Revised December 2005

Accepted December 2005

\begin{abstract}
Purpose - The purpose of this paper is to confirm predictions that employee reports of psychological climate, appraisals of change and levels of adjustment during a change programme would be more positive for employees in higher status groups (operationalized as hierarchical level in the organization and occupational role).

Design/methodology/approach - Two questionnaire studies were conducted and data were analysed using Multivariate Analysis of Variance (MANOVA). Study one examined differences among 669 public sector employees as a function of status (organizational hierarchal level). Study two examined differences among 732 hospital employees as a function of role (occupational group) and status (managerial responsibility).

Findings - The results of study one revealed that upper level staff reported more positive attitudes during change, across a range of indicators. The results of study two showed that non-clinical staff reported more negative attitudes during change than other occupational groups. In addition, managers appraised change as more stressful than non-managers, but felt more in control of the situation.

Research limitations/implications - A limitation of the paper is the cross sectional and self-report nature of measurement. Future research could utilize a longitudinal design and collect alternative sources of data to indicate the constructs of interest, e.g. supervisor ratings of employee adjustment during change.

Practical implications - Together, the results of both studies highlighted the importance of implementing change management interventions that are targeted at the sub-group level.

Originality/value - The findings of the paper add empirical evidence to the emerging literature on group differences in adjustment during organizational change. The paper will be of interest to academics and practicing managers, particularly those concerned with the effective management of change programmes.
\end{abstract}

Keywords Employees, Employee attitudes, Organizational change

Paper type Research paper

The research reported in this article was supported by a Strategic Partners Industry, Research and Training grant held by V. Callan, C. Gallois, E. Jones and P. Bordia. Financial support from the Schools of Management and Applied Psychology at Griffith University is also acknowledged. In addition, many thanks are due to Stephen Cox for his assistance with the structural equation analyses and Bernadette Watson for her assistance with data collection.

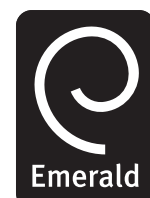

Journal of Managerial Psychology Vol. 21 No. 2, 2006 pp. $145-162$

(C) Emerald Group Publishing Limited 0268-3946 DOI $10.1108 / 02683940610650758$ 
JMP

21,2

146

The increasing pace of global, economic and technological development makes change an inevitable feature of organizational life (Cummings and Worley, 1997). Despite the pervasiveness of corporate change, the majority of change initiatives fail to achieve their strategic objectives. It has been argued that most failures are due to human factors such as change-related responses, attitudes and behaviours (Kotter, 1995). Employee attitudes toward organizational change affect not only the overall success of the change process but other important outcomes such as employee satisfaction.

Recent research has suggested that a healthy psychological climate can facilitate positive adjustment among employees experiencing the implementation of organizational change. Martin et al. (2005) proposed a theoretical model of employee adjustment during organizational change by drawing on the cognitive phenomenological model of stress and coping (Lazarus and Folkman, 1984). The model conceptualized aspects of psychological climate as coping resources, or antecedents to more positive appraisals of change, and as predictors of adjustment during change. The model was tested using structural equation modelling to examine the relationships among these variables. The results of this study showed overall support for the model tested, and confirmed several important sets of variables in the complex process of employee adjustment during organizational change, i.e. psychological climate, change appraisal and adjustment indicators. However, the authors identified that the investigation of meaningful differences among these variables at the sub-sample (group) level was an important direction for future research, especially in relation to the applied significance of the model.

Indeed, most of the organizational change literature fails to distinguish between the diversity of participants in change programmes, treating them as a single entity (Armstrong-Stassen, 1998; Larkin and Larkin, 1994; Lewis, 1999). This is despite the fact that social-psychological theory tells us that group membership and group status are potentially salient sources of identity-driven variation in employee cognition, affect and behaviour (Ashforth and Mael, 1989; Hennessy and West, 1999; Kramer, 1991). Employees may identify as members of groups based on characteristics such as gender, ethnicity, role or occupation, position in the hierarchy, work unit or department/division, and union membership. Terry and Callan (1998) noted that organizational change is an event that tends to make group identity highly salient to employees. Groups may have varying levels of status that are dependent on the particular culture and norms within an organization. The present research focuses on two important determinants of a group's status: hierarchical level and occupational role.

\section{Hierarchical level}

An employee's position in the organizational hierarchy is an important structural variable, which influences a range of organizational attitudes and behaviours (Katz and Kahn, 1978). For example, differences in the way organizational communication is perceived are often dependent on the superior or subordinate status of employees (Hatfield and Huseman, 1982; Jablin and Putnam, 1987). Organizational change can be conceptualized as a political event with employees of different status having differential amounts of power and playing different roles (Schein, 1985). De Luca (1984) grouped change participants as "controllers, targets and interventionists" and Kanter et al. (1992) classified them as "change strategists, change managers and change recipients". A small number of studies have suggested that an employee's position in the hierarchical structure of an organization is associated with differences in perceptions of change or downsizing (Armstrong-Stassen, 1998; Olson and Tetrick, 
1988; Watson et al., 2005), the communication of change (Bordia et al., 2005) and acceptance of organizational change (Ahmad, 2000). It has been proposed that these differences stem from those at higher levels in the hierarchy having more control over decisions concerning the future of their jobs (Armstrong-Stassen, 1998). In addition, managers are more involved in the change process, and in a sense "drive" the changes, they have more expedient access to information and greater understanding of the rationale for change (Haugh and Laschinger, 1996; St Amour, 2001). In contrast, lower level employees may feel disempowered and less confident during organizational change (Haugh and Laschinger, 1996).

\section{Occupational role}

Beck et al. (2000) noted a growing interest in professional identity as a primary social or organizational identification category for employees. In hospitals, "micro-climates" based on occupational role such as nursing, medicine and administration have a strong influence on employees' attitudes, values and behaviours (Degeling et al., 1998). Group memberships that reflect task orientation have also been significantly associated with different levels of perceived work stress (Winefield, 2000). Also, as outlined above, higher status staff may experience less threat of negative consequences from change than lower status staff (Kanter et al., 1992). It follows that professional or occupational identity and the status associated with one's occupational group may be an important correlate of change perceptions, particularly where the proposed change threatens established professional groups (Covin and Kilmann, 1990; Watson et al., 2005).

As outlined above, a small amount of literature on group differences in perceptions of change has begun to emerge, however it is certainly an area that requires further investigation. The present research aimed to investigate the extent to which employee adjustment during change varies as a function of differing status and role groupings. As stated earlier, adjustment during an organizational change event is theorized as consisting of three sets of variables: perceptions of psychological climate, change appraisals and adjustment indicators (Martin et al., 2005). Each of the elements of the theoretical framework employed in the present research is now briefly discussed.

\section{Psychological climate}

Psychological climate is conceptualized as a multidimensional construct comprising an individual's psychologically meaningful representations of proximal organizational structures, processes and events (such as job, role, leader, work group and organizational characteristics) that plays a key role in explaining employee responses to organizational change (Armenakis and Bedeian, 1999; Parker et al., 2003; Pettigrew, 2000). Schneider (2000, p. 21) claimed that:

... changes in the variables associated with climate might provide a useful entree to achieving the changes in behaviour that will result in changes in the more fundamental beliefs and values required for durable organizational change.

However, Schein (2000) argued that not all elements of climate are equally potent in the degree to which they determine employee behaviour. Accordingly, a number of recommendations about how climate should be measured have been made. Payne (2000) argued that climate scales should be designed in collaboration with members of the organization to increase their ecological validity. Qualitative research can tell us which elements of an organization's climate are more salient to employees and are, thus, potentially stronger determinants of adjustment during change. Attention has also been 
JMP

21,2

148

directed towards the measurement of climate dimensions that apply to non-employee stakeholder groups such as customers or other stakeholders (Burke et al., 2002).

The present research examined psychological climate in two organizations. The climate construct was operationalized according to the aforementioned assertions of Payne (2000) and Burke et al. (2002). Thus, a unique climate dimension, theorized to be important in predicting employee perceptions of change was determined through interviews in each of the organizations studied. Second, a measure of the stakeholder dimension of climate was adapted for relevance in each of the organizations. Third, due to the robust findings regarding social support and Michela and Burke (2000) argument that climate is influenced substantially by behaviours of the supervisor such as listening and providing feedback, supervisor support was also theorized as a generic dimension of climate in both organizations.

\section{Change appraisal}

The construct of appraisal is central to understanding whether an individual will experience stress in a given situation. Primary appraisal represents a person's cognitive evaluation of how a situation or event will affect their level of well-being or how 'stressful' they perceive it to be (Lazarus and Folkman, 1984). If a situation is considered to be potentially stressful, a secondary form of appraisal is activated, consisting of two distinct judgements about the situation: perceived controllability and efficacy expectations (Terry et al., 1996). Control is a construct central to our understanding of psychological functioning and adjustment (Karasek, 1979; Terry and Jimmieson, 1999). Perceived controllability represents the individual's judgement about whether they have any capacity to remove or modify the stressor. A person's efficacy expectancy, or their level of confidence in their ability to perform the behaviours necessary to deal with a stressor, is also a generally accepted determinant of adjustment (Bandura, 1982), particularly in situations such as career change and job insecurity (Judge et al., 1999). It is important to note that control and self-efficacy are multifaceted constructs and are best measured in relation to a specific aspect of the work environment (Bandura, 1982; Ganster et al., 1986). In the present research, the appraisal constructs were measured specifically in relation to a programme of organizational change, i.e. change-related stress, change-related self-efficacy and change-related control.

\section{Adjustment indicators}

The success of organizational change initiatives is often determined by employee attitudes towards the change (Beer et al., 1990). In addition to their effect on the success of a change initiative, employee attitudes toward a pending change can have a wider impact in terms of overall job satisfaction, organizational commitment, morale, productivity, absenteeism and turnover intentions. These indicators can serve as markers for tracking the likelihood of employees enacting behaviours necessary for achieving the desired changes (Eby et al., 2000; McManus et al., 1995; Wanberg and Banas, 2000). In the present research, a range of variables were conceptualized as indicators of adjustment during change. In the first organization studied, adjustment indicators included organizational commitment and other more distal outcomes of interest to organizations, such as turnover and absenteeism. In the second organization, job satisfaction and psychological well-being were measured as adjustment indicators. 


\section{Aims of the present research}

Although there is little empirical literature on group differences in adjustment during change, the literature reviewed above provides some justification for predicting status and role-based variation in the variables theorized as indicative of employee adjustment during organizational change. In particular, the aspect of control over the processes and consequences of change and differences in the need for information were identified as important differences between employees at different levels in the organizational hierarchy. It is argued that these differences may be a source of variation in change related attitudes. Hence, Study one aimed to test the following hypothesis:

H1. The lower an employees position in the organizational hierarchy, the more likely they will be to report better perceptions of psychological climate, more positive appraisals of change and higher levels of the indicators of adjustment during change.

Moreover, social-psychological theory suggests that the status of the group an employee identifies with is a potential determinant of variation in employee adjustment during organizational change. In some organizations, members of high status occupations may also have increased control over the processes and consequences of change. Hence, Study two aimed to test the following hypothesis:

H2. Employees who are members of higher status groups within an organization (according to occupational role) will report better perceptions of psychological climate, more positive appraisals of change and higher levels of the indicators of adjustment during change.

\section{Method}

Study one

Procedure. Study one was conducted in a large, state public sector organization that had undergone significant change and restructuring, including an amalgamation and de-amalgamation with another department. The research was conducted during on-going changes to the organization. An anonymous, self-administered questionnaire was mailed to all staff with a reply paid envelope in which to return it. The questionnaire included a supportive cover letter from the CEO.

Sample. Of the 1,283 questionnaires distributed, 877 completed questionnaires were received, representing a 68.4 per cent response rate. The sample was 47 per cent male and 53 per cent female. Ages ranged from under 20 years to over 50 years, and 26-30 years was the most frequently selected category. Over half the participants had worked in the department for at least four years and the majority were permanent full time workers (72 per cent). Occupational categories represented were: direct client contact (21 per cent), administrative (20 per cent), management (15 per cent), technical/professional (11 per cent), trade staff ( 6 per cent), policy/planning ( 6 per cent), secretarial ( 5 per cent), project work (11 per cent) and other (5 per cent). Overall, comparisons on key demographic variables using departmental statistics revealed that the sample was representative of the organization's workforce. Cases that were not in the administrative officer (AO) staff classification were excluded from the analysis so that a single occupational group with a large sample size could be examined. Once these cases were removed, the original sample of 877 participants was reduced to 669 participants.

Measures: Independent variable. Participants provided demographic information and selected one of six job types. Informal interviews with staff revealed that

\section{Employee \\ adjustment}

149 
JMP

21,2

150

hierarchical level-based identity was the most salient group variable in the public service environment. Interviewees commented on the public sector "ladder" analogy, indicating that the various staff classification levels (e.g. A01-A08) were often used as labels for employees. On the basis of these interviews and the staff classifications provided by survey participants, three groups of employees were created, reflecting their organizational level. These groupings were made in consultation with staff of the organization to ensure that the divisions were meaningful and not arbitrary. The three categories created were: lower level employees (A01-A03, e.g. base-grade administrative, clerical and customer service roles); middle level employees (A04-A06, e.g. policy, research and supervisory roles); and upper level employees (A07-A08, e.g. unit managers, senior policy officers and senior executives).

Dependent variables. Three measures of psychological climate were obtained: customer service, leader vision and the availability of social support from direct supervisors. Customer service was measured with seven items that assessed the stakeholder dimension of climate (e.g. "we achieve high levels of client satisfaction"; $1=$ strongly disagree to $6=$ strongly agree). These items were developed for use in the present research in conjunction with staff of the organization. The scale reliability coefficient alpha was 0.86 . The interviews also revealed that visionary leadership during the change process was a particularly salient aspect of psychological climate to employees in this organization. Hence, an organization-specific measure of climate was obtained by including a leader vision scale that consisted of six items taken from Kouzes and Posner's (1993) Leadership Practices Inventory (e.g., "senior staff show excitement about future possibilities"; $1=$ strongly disagree to $6=$ strongly agree). A generic element of psychological climate was obtained in the form of a measure of the perceived availability of social support. Employees reported how much they relied on their direct supervisor for various types of emotional and informational support using six items rated on a four point scale (e.g., $1=$ very much to $4=$ not at all). These questions were selected from items used by Terry et al. (1996).

Change appraisals were assessed using three measures: change stress, change self-efficacy and change control. Each of these scales were used by Terry et al. (1996). Perceived change-related stress was measured using four items. These questions asked participants to rate the change process on six point bipolar scales regarding the level of stress, disruption, difficulty and extent of upset (e.g., $1=$ not at all stressful and $6=$ extremely stressful). Self-efficacy was assessed with four items (e.g., "I am confident in my ability to deal with the planned structural changes", $1=$ strongly disagree and $5=$ strongly agree). Change control was measured with three items (e.g., "I will be able to influence the extent to which the changes will affect my job", $1=$ strongly disagree and $5=$ strongly agree).

Three indicators of adjustment were measured: organizational commitment, turnover intentions and absenteeism. Organizational commitment was assessed with five items adapted from Mowday et al. (1979). The scale assesses generalized levels of commitment (e.g., "What happens in the department is really important to me; $1=$ strongly disagree and $5=$ strongly agree). Turnover intentions were measured with six items adapted from those used by Fried and Tiegs (1995) and Meyer et al. (1993) (e.g., "I am planning to search for a new job within the next 12 months"; 1 = strongly disagree and $7=$ strongly agree). A measure of self-reported absenteeism was obtained using the procedure outlined by Parker and Kulik (1995). Organizations often resist providing records-based data and make participant anonymity a condition for access. Hence, many studies have used self-report measures to assess absenteeism 
(Johns, 1994). Participants were asked to estimate the number of days they had been absent due to reasons other than physical ill health or leave entitlements "e.g., feeling depressed or stressed, emotionally run down, taking a 'sickie', unfair workload, difficult work relationships."

\section{Study 2}

Procedure. The research was conducted in a large public hospital where employees were experiencing the introduction of large-scale organizational change. Changes included the redevelopment of the hospital site, downsizing of staff and significant structural and cultural change including the implementation of multi-disciplinary teams. The research was conducted whilst the change management unit were in the midst of planning the changes including the design of the new building, organizational structure and work practices. All hospital staff were mailed an anonymous, self-administered questionnaire with a postage-paid, return envelope. A supportive cover letter from the CEO was attached.

Sample. A total of 779 surveys were returned for analysis, providing a 49 per cent response rate. Due to the need to examine the occupational group variable, cases with missing data in relation to staff classification were excluded from the analysis. Once these cases were removed, the original sample of 779 participants was reduced to 732 participants.

The sample consisted of 70 per cent women and 30 per cent men, with 62 percent of participants aged 20 to 40 years and 38 per cent aged 41 and over. Most of the participants (37 per cent) had been working at the hospital for a period of two to five years and a large number (23 per cent) had worked there from six to ten years. The occupational categories represented in the sample were medical managers (1 per cent), medical clinicians ( 7 per cent), nurse managers ( 5 per cent), nurse clinicians ( 41 per cent), junior medical officers (1 per cent), other health professionals - managers ( 3 per cent), other health professionals - clinicians (10 per cent), non-clinical managers ( 2 per cent), non-clinical supervisors (3 per cent), operational, administrative, technical and trade officers (20 per cent), executives ( 1 per cent) and others (6 per cent). Analysis of hospital statistics showed that the sample was representative of the composition of the organization's workforce.

Measures: independent variables. Participants provided demographic information and selected one of 12 staff classifications to describe their position. Interviews with hospital staff revealed that occupational identity was the most salient sub-group variable in the hospital environment. Divisions between groups were often made based on whether the employee was, for example, a doctor or a nurse rather than what status level they were or work unit they worked for. Interview participants commented that although multidisciplinary teams were used to deliver service to patients, these professional divisions still existed. Hence, staff classifications were reduced from 12 categories to four major occupational groups (non-clinical, allied health, medical and nursing). Re-classifying the staff into these groups was a simple task and did not require any reliability checking. Computerized recoding of the datafile created the new occupational variable. The group labelled non-clinical staff comprised a wide variety of staff including administrative officers, receptionists, ward assistants, cleaning/catering staff and operational/trade staff. The groups labelled medical, nurses and allied health professionals were made up of clinical practitioners of medicine, nursing and allied health specialities (e.g. psychology, occupational therapy, dietetics, physiotherapy, audiology) respectively. It is commonly accepted that medical
Employee adjustment 
JMP

21,2

152

staff are the highest status occupational group and non-clinical staff are the lowest status group in this organization.

Although occupational group differences are proposed to be salient in this particular sample, the influence of hierarchical level was also controlled for by simultaneously examining the status of participants. The staff classification data enabled participants to be divided into two groups: managers and staff. Non-clinical managers and supervisors generally co-ordinated the services of non-clinical support staff. The clinical managers were senior doctors, nurses and allied health professionals who manage the provision of clinical services.

Dependent variables. As in study one, three measures of psychological climate were obtained: quality of patient care, employee relations and the availability of social support from direct supervisors. The focus on the quality of patient care comprised the stakeholder dimension of climate and was measured using four items developed for use in the survey in conjunction with hospital staff. Using a six point scale, staff rated the extent of agreement with statements such as: "In my view, the hospital provides good quality patient care", ( $1=$ strongly disagree to $6=$ strongly agree). The scale reliability coefficient alpha was 0.81 . The interviews revealed that a particularly salient element of psychological climate during the change planning process was the nature of relationships between employees. Hence, an organization specific variable, employee relations, was measured with three items that asked staff to rate their level of agreement with statements about different aspects of working at the hospital (e.g., "Staff treat each other with respect"; $1=$ strongly disagree to $6=$ strongly agree). The scale reliability coefficient alpha was 0.78 . Again, a generic dimension of climate was measured in the form of a scale assessing social support from supervisors. This measure is the same as that described in study one.

Three types of change appraisal were measured: perceived stress, control and self-efficacy. These scales were also the same as those described in study one.

Two indicators of adjustment were obtained: job satisfaction and psychological well-being. Job satisfaction was assessed with five items adapted from those used by Caplan et al. (1975). The scale assesses generalized levels of job satisfaction (e.g., "All things considered, how satisfied are you with your job?; $1=$ very dissatisfied to $5=$ very satisfied). Psychological well-being was measured with six items from Goldberg's (1972) psychological symptoms scale of the General Health Questionnaire (GHQ-12). Participants were asked to estimate how often they experienced six different negative psychological health symptoms, using a 4 point scale (e.g., "Felt constantly under strain", $1=$ not at all to $4=$ much more than usual). The scores on these items were reversed to provide an assessment of psychological well-being.

\section{Results}

There was no evidence of multicollinearity among the variables in either data set. None of the variables was significantly skewed with the exception of the absenteeism data in study one (skew $=14.70, \mathrm{SE}=0.085$ ). This common problem is due to the number of staff who have zero days absent (Hemingway and Smith, 1999). Even with various types of transformation, the distribution did not approach normality, meaning that a key assumption for statistical analysis would be violated. These data were re-coded into a dichotomous variable $(0=$ not absent, $1=$ absent $)$ so that the data could still be investigated for group differences using a non-parametric test.

Confirmatory factor analyses (Bollen, 1989) revealed that the items proposed to measure each of the dependent variables demonstrated good fit to the data (study one: 
$\chi^{2}(296)=688, p<0.001, \chi^{2} / \mathrm{df}=2.32, \quad \mathrm{CFI}=0.97$, RMSEA $=0.04 ;$ study two: $\left.\chi^{2}(279)=499, \quad p<0.001, \quad \chi^{2} / \mathrm{df}=1.84, \quad \mathrm{CFI}=0.97, \quad \mathrm{RMSEA}=0.03\right) . \quad \mathrm{A}$ basic assessment of common method variance was also undertaken by testing a one-factor models, which did not fit the data well (study one: $\chi^{2}(324)=8337$, $p<0.001, \chi^{2} / \mathrm{df}=25.73, \mathrm{CFI}=0.45$, RMSEA $=0.17$; study two: $\chi^{2}(275)=4548$, $\left.p<0.001, \chi^{2} / \mathrm{df}=16.5, \mathrm{CFI}=0.46, \mathrm{RMSEA}=0.14\right)$. These results suggest that common method variance did not pose a substantial threat to the validity of the measured constructs (Harris and Mossholder, 1996).

Multivariate analysis of variance (MANOVA) was utilized to examine group differences in ratings of climate, change appraisal and adjustment indicators. In study one, three one-way MANOVAS were performed to assess separately the effects of organizational level on the dimensions of climate, change appraisals and adjustment indicators. Main effect was assessed with Wilks' lambda. Differences between groups for significant univariate effects were assessed with post-hoc tests (Student-Newman Keuls). Table I shows the significant multivariate and univariate effects. Table II shows the group means for each of the significant and trend effects and the results of the post-hoc analyses. Tables presenting the means and standard deviations for all variables by each of the levels are available upon request.

The first MANOVA was conducted to assess differences between three hierarchical levels on three climate variables: leader vision, service orientation and supervisor

\begin{tabular}{|c|c|c|c|c|c|c|c|}
\hline $\begin{array}{l}\text { Significant } \\
\text { multivariate }\end{array}$ & $F$ & $\mathrm{df}$ & $\eta^{2}$ & $\begin{array}{l}\text { Significant } \\
\text { univariate }\end{array}$ & $F$ & $\mathrm{df}$ & $\eta^{2}$ \\
\hline Climate & $5.98^{*}$ & 6,1328 & 0.026 & $\begin{array}{l}\text { Leader vision } \\
\text { Supervisor support }\end{array}$ & $\begin{array}{l}13.68^{* * *} \\
3.94^{*}\end{array}$ & $\begin{array}{l}2,666 \\
2,666\end{array}$ & $\begin{array}{l}0.039 \\
0.012\end{array}$ \\
\hline Appraisal & $12.03^{* * *}$ & 6,1336 & 0.051 & $\begin{array}{l}\text { Change self-efficacy } \\
\text { Change control }\end{array}$ & $\begin{array}{l}3.30^{*} \\
34.68^{* * *}\end{array}$ & 2,670 & $\begin{array}{l}0.010 \\
0.094\end{array}$ \\
\hline Adjustment & $3.59^{* * *}$ & 4,1362 & 0.015 & $\begin{array}{l}\text { Organizational commitment } \\
\text { Turnover intentions }\end{array}$ & $\begin{array}{l}7.71 * * * \\
2.56 * * *\end{array}$ & $\begin{array}{l}2,685 \\
2,685\end{array}$ & $\begin{array}{l}0.022 \\
0.007\end{array}$ \\
\hline
\end{tabular}

Notes: ${ }^{*} p<0.05 ;{ }^{* *} p<0.01 ;{ }^{* * *} p<0.001 ;{ }^{* * * *} p<0.10$

\section{Employee adjustment}

153

Table I.

Significant multivariate and univariate effects

\begin{tabular}{|c|c|c|c|c|}
\hline & Lower level & Middle level & Upper level & \\
\hline \multicolumn{5}{|l|}{ Climate } \\
\hline Leader vision & 3.49 & 3.60 & $4.24^{*}$ & \\
\hline Supervisor support & 2.88 & 3.04 & $3.15^{* *}$ & \\
\hline \multicolumn{5}{|l|}{ Change appraisal } \\
\hline Change self-efficacy & 4.10 & 4.11 & $4.30 *$ & \\
\hline Change control & 3.61 & $3.96^{* *}$ & $4.81^{*}$ & \\
\hline \multicolumn{5}{|l|}{ Adjustment } \\
\hline Organizational commitment & 3.91 & 4.01 & $4.30 *$ & $\begin{array}{l}\text { Table II. } \\
\text { Mean }\end{array}$ \\
\hline Turnover intentions & 3.45 & 3.09 & 3.20 & $\begin{array}{l}\text { Mean scores of } \\
\text { sionificant results and }\end{array}$ \\
\hline \multicolumn{5}{|c|}{$\begin{array}{l}\text { Notes: }{ }^{*} \text { This mean is significantly different from all other means in this row; }{ }^{* *} \text { This mean is } \begin{array}{r}\text { post hoc tests for } \\
\text { significantly different from the first group in this row }\end{array}\end{array}$} \\
\hline
\end{tabular}


JMP

21,2

154

support. A significant overall multivariate effect was obtained. Inspection of univariate effects found a significant difference between groups on the measures of leader vision and supervisor support. Post-hoc tests indicated that upper level employees reported significantly higher levels of leader vision than middle and lower level employees and significantly higher levels of supervisor support than lower level employees.

A second MANOVA was conducted to assess differences between three hierarchical levels on three change appraisals: change stress, self-efficacy and control. A significant overall multivariate effect was obtained. Inspection of univariate effects found a significant difference between groups for change self-efficacy and change control. Post-hoc tests indicated that upper level employees reported significantly higher levels of change self-efficacy than middle or lower level employees. Upper level employees also reported significantly higher levels of change control than middle and lower level employees. In addition, middle level employees reported significantly higher levels of change control than lower level employees.

A third MANOVA was conducted to assess differences between three hierarchical levels on two of the three adjustment indicators: organizational commitment and turnover intentions. A significant overall multivariate effect was obtained. Inspection of univariate effects found a significant difference between groups on the measure of organizational commitment. A trend $(p=0.08)$ was found for turnover intentions. Post-hoc tests indicated that upper level employees reported significantly higher levels of organizational commitment than middle and lower level employees. The trend effect for turnover intentions suggested that lower level staff were more likely to report intending to leave their job than middle or upper level staff although this finding should be interpreted with caution as it was not statistically significant at $p<0.05$.

Differences between groups for the third adjustment indicator (dichotomous absenteeism variable) were assessed using cross tabulations and chi-square analyses. No significant differences between groups for whether or not employees were absent due to work-related reasons were found $\left(\chi^{2}=14.83\right.$, $\left.\mathrm{df}=2 ; p<0.001\right)$.

In study two, three two-way MANOVAs were run to separately assess the effects of the between subjects variables (role and status), and any interaction between them, on the dimensions of climate, change appraisals and adjustment indicators. The significant and trend results are presented in Table III and the means and results of the post-hoc analyses for these variables are shown in Table IV. Tables presenting the means and standard deviations for all variables by occupation, organizational level and occupation by organizational level are available upon request.

The first MANOVA was conducted to assess differences between four occupational groups and two hierarchical levels on each of the climate indicators (employee relations,

\begin{tabular}{|c|c|c|c|c|c|c|c|}
\hline Significant multivariate & $F$ & $\mathrm{df}$ & $\eta^{2}$ & Significant univariate & $F$ & df & $\eta^{2}$ \\
\hline Climate & $1.96 *$ & 9,1757 & 0.008 & \multirow{3}{*}{ Employee relations } & \multirow{3}{*}{$4.10^{* *}$} & \multirow{3}{*}{3,724} & \multirow{3}{*}{0.017} \\
\hline Occupation & & & & & & & \\
\hline Change appraisal & $3.39^{*}$ & 3,723 & 0.014 & & & & \\
\hline Level & & & & Change stress & $3.07^{* * * *}$ & 1,725 & 0.004 \\
\hline Level $\times$ Occunation & $203 *$ & 9. 1759 & 0008 & $\begin{array}{l}\text { Change control } \\
\text { Change stress }\end{array}$ & $\begin{array}{l}5.55^{*} \\
3.43^{*}\end{array}$ & $\begin{array}{l}1,725 \\
3725\end{array}$ & 0.008 \\
\hline * & & $*$ & 0.000 & Clid & & 3,125 & \\
\hline
\end{tabular}

Table III.

Significant multivariate and univariate effects
Note: ${ }^{*} p<0.05 ;{ }^{* *} p<0.01 ;{ }^{* * *} p<0.001 ;{ }^{* * * *} p<0.10$ 


\begin{tabular}{|c|c|c|c|c|c|c|}
\hline & Medical & Nursing & Allied health & Non-clinical & Overall & $\begin{array}{l}\text { yee } \\
\text { ent }\end{array}$ \\
\hline \multicolumn{7}{|c|}{ Employee relations } \\
\hline Managers & 4.55 & 4.29 & 4.35 & 4.11 & \multicolumn{2}{|l|}{4.33} \\
\hline Non-managers & 4.01 & 4.06 & 4.65 & 3.64 & \multirow[t]{2}{*}{4.09} & \\
\hline Overall & 4.09 & 4.09 & $4.59^{* *}$ & $3.72^{*}$ & & \\
\hline \multicolumn{7}{|l|}{ Change stress } \\
\hline Managers & 3.47 & $3.84^{* * *}$ & 3.22 & 3.35 & \multirow{3}{*}{$\begin{array}{l}3.47^{* * *} \\
3.18\end{array}$} & \\
\hline Non-managers & 2.94 & 3.15 & 2.95 & $3.68^{*}$ & & \\
\hline Overall & 3.02 & 3.22 & 3.00 & 3.61 & & \\
\hline \multicolumn{7}{|l|}{ Change control } \\
\hline Managers & 3.00 & 2.91 & 2.94 & 2.55 & \multicolumn{2}{|l|}{$2.85^{* * *}$} \\
\hline Non-managers & 2.28 & 2.72 & 2.67 & 2.64 & \multirow[t]{2}{*}{2.58} & \\
\hline Overall & 2.39 & 2.74 & 2.72 & 2.62 & & $\begin{array}{l}\text { Table IV. } \\
\text { Mean scores for }\end{array}$ \\
\hline \multicolumn{7}{|c|}{$\begin{array}{l}\text { Notes: }{ }^{*} \text { This mean is significantly different from all other means in this row; }{ }^{* *} \text { This mean is } \\
\text { significantly different from the medical and nursing groups; }{ }^{* * *} \text { This mean for managers is different } \\
\text { from the mean for non-managers }\end{array}$} \\
\hline
\end{tabular}

patient care and supervisor social support). A significant overall multivariate effect was obtained for occupational group. Inspection of the univariate effects found a significant difference between occupational groups on the measure of employee relations. Post-hoc tests indicated that non-clinical staff rated employee relations as less effective than nursing, medical and allied health staff. In addition, allied health professionals rated employee relations as more effective than nursing and medical staff.

A second MANOVA was conducted to assess differences between four occupational groups and two hierarchical levels on change appraisals (change stress, self-efficacy and control). A significant overall multivariate effect was obtained for organizational level and for the interaction between occupation and organizational level. Inspection of the univariate effects found a significant difference between organizational levels for change control and a trend for change stress, $p=0.08$ (the interpretation of which is subsumed by the interaction presented below). Analyses of simple effects showed that managers rated their level of change control higher than non-managers. In addition, there was a significant multivariate interaction between occupation and organizational level. The only significant univariate difference was found on the measure of change stress. Analyses of simple effects revealed that nurses who were managers reported significantly higher levels of change stress than nurses who were not managers $(p<0.01)$. In addition, within the non-managerial staff, the non-clinical group rated the change as more stressful than the allied health, medical or nursing groups $(p<0.001)$.

A third MANOVA was conducted to assess differences between four occupational groups and two hierarchical levels on two adjustment indicators: job satisfaction and psychological well-being. No significant overall multivariate effect was obtained.

\section{Discussion}

The aim of study one was to test the prediction that upper level staff would be more positive in their reports of perceptions of climate, change appraisals and indicators of employee adjustment during change. Although there were similarities between the groups, a number of significant differences that supported the hypothesis were found, 
JMP

21,2

156

and provide some confirmation of the emerging literature on group differences in attitudes during change processes (Ahmad, 2000; Armstrong-Stassen, 1998; Bordia et al., 2005; Olson and Tetrick, 1988; Watson et al., 2005).

Upper level employees reported higher levels of supervisor support than the lower level staff. Lower level staff may feel less support from their supervisors as their supervisors are occupied with implementing change. Lower level employees have been shown to report more equivocality during change than upper level employees (Miles et al., 1996) and this uncertainty may also be associated with decreased satisfaction with their supervisor. In contrast, managers and supervisors have been shown to report high levels of supervisory support (Haugh and Laschinger, 1996).

Upper level staff had more positive perceptions about the extent to which leaders exhibited a vision for the organization than middle or lower level staff. Senior staff are often more aware of the vision for the organization. In the organization studied, the upper level group was comprised of senior policy officers and unit managers for whom an understanding of the vision for the organization was an integral part of their role. It is also important to note that upper level staff have much more contact with the CEO and leadership of an organization (Young and Post, 1993) and, thus, have more opportunity to appraise their leadership behaviours.

Upper level staff also appraised change more positively, with significantly higher levels of perceived control over the changes and confidence in their ability to continue to perform well. These results support the initial findings reviewed earlier. Furthermore, the increased control that managers perceive is also likely to promote better coping responses. Armstrong-Stassen (1998) found that supervisors were more likely to engage in control-oriented coping, compared to the coping strategy of avoidance typically employed by non-supervisors (Olson and Tetrick, 1988). Positive coping strategies such as these have also been linked to better adjustment during stressful situations (Terry et al., 1996).

Upper level staff demonstrated better adjustment during change in relation to higher levels of organizational commitment. Commitment is generally higher among more senior staff (Ahmad, 2000; O'Driscoll and Randall, 1999). Commitment may be higher on the part of more senior members of staff because the pro-social, extra-role behaviours and higher level of performance associated with higher commitment would have been instrumental in securing promotion for such individuals (Bennett and Durkin, 2000). Lower level staff reported greater turnover intentions. However, this result should be interpreted with caution as the effect was not significant using the conventional criteria $(p<0.05)$.

The aim of study two was to test the prediction that higher status occupational groups would be more positive in their reports of perceptions of climate, change appraisals and indicators of employee adjustment during change. Despite the surprisingly small number of differences, the results confirmed that hospital "micro-climates" based on occupational groups may have some influence on employee attitudes (Degeling et al., 1998). In examining the differences that were found, a pattern of results that provide some support for the hypothesis was evident. Non-clinical staff were more likely than other groups to report more negative perceptions of climate and change. They reported the highest levels of change stress and the poorest evaluations of the effectiveness of employee relations within the hospital. These results may be explained by the fact that non-clinical (support) staff were the lowest status group, and hence were likely to fare worse than the other occupational groups during 
organizational change, particularly in relation to downsizing and the amount of political influence they could to exert.

In contrast, allied health professionals reported the most positive perceptions of employee relations. Although they were not the highest status group in the hospital (medical), in the context of the organization, interviews showed that allied health staff had good levels of morale in comparison to other groups of staff. Over the past decade, major efforts have been made to develop a strong source of group identification, "allied health professionals", for the various clinical (but not medical or nursing) staff working in hospitals. This strong inter-group identity may act as a buffer against the stress of organizational change (Terry et al., 1996). Also, in this particular change context, issues such as competition for resources and downsizing were not as relevant to allied health professionals as they were for other groups.

Interestingly, there were fewer differences between organizational levels than in study one. There were many similarities between managerial and non-managerial staff. However, it is important to note that the interviews revealed that hierarchical level was not the most salient source of group identity and it was included more as a control variable. The major difference between organizational levels was in their appraisals of change. As in study one, managers reported significantly higher levels of change control than non-managers. Although it should be interpreted with caution, there was also a trend for them to report higher levels of change stress. Managers may have more control over the change process, but it could also be argued that the managerial responsibility for this process places increased pressure on this group, which explains the higher levels of stress. In addition, these managers often have to deal with increased hostility and or uncertainty from employees in response to the changes. Watson et al. (2005) found that managers were more likely to report dealing with conflict as a negative aspect of change than lower level employees. Callan and Dickson (1992) found that managers experience high levels of stress during change due to a range of pressures. In addition, when the interaction between occupation and organizational level was examined, it was evident that nursing managers reported more stress than nursing staff. Nursing managers complained that patient care was being compromised by the changes and being responsible for dealing with this may be a source of stress to this particular group.

Across both studies, some general patterns in the results were observed. Employees' appraisals of change were the group of variables that most consistently differed according to status. In particular, change control was higher for upper level or managerial staff in both studies. Change related self-efficacy was higher for upper level staff study one. Change related stress was higher for managers than non-managers in study two.

\section{Implications for change management}

The results of the present research have some important implications for promoting positive employee adjustment during organizational change. Both studies found differences among climate, appraisal and adjustment variables according to employees' occupational role and/or hierarchical level. These differing perceptions and outcomes can create problems for the effective implementation of organizational change. Change agents should consider the needs of different organizational groups in order to achieve effective and successful change by using informed diagnostic data. Diagnostic processes should pay attention to the salient groupings of staff within an organization so that interventions can be specifically targeted. Michela and Burke (2000, p. 240) asserted that 
JMP

21,2

158 “diagnosing and monitoring employees' beliefs, perceptions, and motivations, especially those related to culture and climate are critical to any change effort". Decision makers should take a more proactive approach to identifying "at risk" groups and embedding strategic interventions in the change agenda (Sargent, 1995). For example, in the second organization studied, managers may benefit from stress management training, whilst non-managerial staff's change appraisals might be improved by increasing their involvement, and, thus, their perceptions of control. The results also suggested that improving employee relations may benefit non-clinical staff in particular.

\section{Limitations and directions for future research}

The differences found between occupational groups and hierarchical levels represent a direction for future research. It should be noted that the effect sizes $\left(\eta^{2}\right)$ in the MANOVA analyses indicated that a very small amount of variance in the dependent variables was due to the influence of employee groupings. Although these differences were interpreted due to their statistical significance, the results will need to be confirmed in future research, perhaps in a wider range of organizational settings. The application of alternative methodologies to the current research agenda should also be considered. The approach taken in the present research was primarily quantitative. In depth qualitative methods would be useful for gathering data that may illuminate some of the differences found between groups. In addition, given that the present research used on cross sectional data, group differences could also be linked to additional sources of data that do not rely on self-report measures and longitudinal designs might be employed.

The results of the current research also provide some indication that the development of a multi-level model of employee adjustment to change would be a useful endeavour. Such techniques allow data that is hierarchical in structure (e.g., employees within departments within organizations) to be fitted to models with several levels that attempt to explain variation in the studied constructs (Rowe, 2000). For example, the predictive effects of the different climate variables on appraisal and adjustment (see Martin et al., 2005) could be partitioned for employees within hierarchical and/or occupational groups within organizations. The ability to examine organizational climate variables at different levels of aggregation would also be particularly useful given the debates about the level at which climate should be measured (Ashkanasy et al., 2000; Glick, 1985; Rousseau, 1985).

\section{Overall conclusions}

The research was conducted in an applied setting with participants who were employees in two diverse organizations undergoing change. The results provided some support for the hypotheses and confirmed the initial findings of other studies that investigated the effects of status on how change is perceived (Ahmad, 2000; Armstrong-Stassen, 1998; Bordia et al., 2005; Olson and Tetrick, 1988; Watson et al., 2005). The findings contribute to the literature by documenting the existence of status and role-based differences in a range of variables specifically associated with an empirically validated, recent theoretical model of employee adjustment during organizational change (Martin et al., 2005). These differences reflected the differing status of the positions and roles of the groups in the organizations studied. The detection of such differences yields important information for change management strategies and should be considered an essential part of the diagnostic function of organization development processes. 


\section{References}

Ahmad, A. (2000), "Organizational commitment versus organizational change: a comparative study of blue-collar and white-collar employees of service manufacturing companies", Social Science International, Vol. 16, pp. 20-32.

Armenakis, A.A. and Bedeian, A.G. (1999), "Organizational change: a review of theory and research in the 1990s", Journal of Management, Vol. 25, pp. 293-315.

Armstrong-Stassen, M. (1998), "The effect of gender and organizational level on how survivors appraise and cope with organizational downsizing", Journal of Applied Behavioural Science, Vol. 34, pp. 125-42.

Ashforth, B.E. and Mael, F. (1989), "Social identity theory and the organization", Academy of Management Review, Vol. 14, pp. 20-39.

Ashkanasy, N.M., Widerom, C.P.M. and Peterson, M.F. (2000), Handbook of Organizational Culture and Climate, Sage, Thousand Oaks, CA.

Bandura, A. (1982), "Self-efficacy mechanisms in human agency", American Psychologist, Vol. 37, pp. 122-47.

Beck, S.E., Kaplan, D., Smith, H. and Moroco, J. (2000), "The behavioural health professional: a mental health professional identity model for the 22nd century", Counseling and Human Development, Vol. 33, pp. 1-17.

Beer, M., Eisenstat, R. and Spector, B. (1990), The Critical Path to Corporate Renewal, Harvard Business School Press, Boston, MA.

Bennett, H. and Durkin, M. (2000), "The effects of organizational change on employee psychological attachment: an exploratory study", Journal of Managerial Psychology, Vol. 15, pp. 126-47.

Bollen, K.A. (1989), Structural Equations With Latent Variables, Wiley, New York, NY.

Bordia, P., Martin, A.J., Jones, E.S., Irmer, B.E., Gallois, C. and Callan, V.J. (2005), "Disseminating information during organizational change: communication channel preferences as a function of organizational level" (manuscript under review).

Burke, M.J., Borucki, C.C. and Kaufman, J.D. (2002), "Contemporary perspectives on the study of psychological climate: a commentary", European Journal of Work and Organizational Psychology, Vol. 11, pp. 325-40.

Callan, V.J. and Dickson, C. (1992), "Managerial coping strategies during organizational change”, Asia Pacific Journal of Human Resources, Vol. 30, pp. 47-59.

Caplan, R.D., Cobb, S., French, J.R.P., Van Harrison, R.V. and Pinneau, S.R. Jr (1975), Job Demands and Worker Health, US Department of Health, Education and Welfare, Washington, DC.

Covin, T.J. and Kilmann, R.H. (1990), "Participant perceptions of positive and negative influences on large-scale change", Group and Organization Studies, Vol. 15, pp. 233-48.

Cummings, T.G. and Worley, C.G. (1997), Organization Development and Change, 6th ed., South Western College Publishing, Cincinatti, $\mathrm{OH}$.

De Luca, J.R. (1984), "Managing the socio-political context in planned change efforts", in Kakabadse, A. and Parker, C. (Eds), Power, Politics, and Organizations: A Behavioural Science View, John Wiley, New York, NY.

Degeling, P., Kennedy, J., Hill, M., Carnegie, M. and Holt, J. (1998), Professional Sub-Cultures and Hospital Reform, The Centre for Hospital Management and Information Systems Research, Sydney.

Eby, L.T., Adams, D.M., Russell, J.E.A. and Gaby, S.H. (2000), "Perceptions of organizational readiness for change: Factors related to employees' reactions to the implementation of team based selling”, Human Relations, Vol. 53, pp. 419-42. 
JMP

21,2

Fried, Y. and Tiegs, R.B. (1995), "Supervisors' role conflict and role ambiguity differential relations with performance ratings of subordinates and the moderating effect of screening ability”, Journal of Applied Psychology, Vol. 80, pp. 282-91.

Ganster, D.C., Fusilier, M.R. and Mayes, B.T. (1986), "The role of social support in the experience of stress at work", Journal of Applied Psychology, Vol. 71, pp. 102-10.

Glick, W.H. (1985), "Conceptualising and measuring organisational and psychological climate: pitfalls in multilevel research", Academy of Management Review, Vol. 10, pp. 601-16.

Goldberg, D.P. (1972), The Detection of Psychiatric Illnesses by Questionnaire, Oxford University Press, Oxford.

Harris, S.G. and Mossholder, K.W. (1996), "The affective implications of perceived congruence with culture dimensions during organizational transformation", Journal of Management, Vol. 22, pp. 527-47.

Hatfield, J.D. and Huseman, R.C. (1982), "Perceptual congruence about communication as related to satisfaction: Moderating effects of individual characteristics", Academy of Management Journal, Vol. 25, pp. 349-58.

Haugh, E.B. and Laschinger, H.S. (1996), "Power and opportunity in public health nursing work environments”, Public Health Nursing, Vol. 13, pp. 42-9.

Hemingway, M.A. and Smith, C.S. (1999), "Organizational climate and occupational stressors as predictors of withdrawal behaviours and injuries in nurses", Journal of Occupational and Organizational Psychology, Vol. 72, pp. 1-10.

Hennessy, J. and West, M.A. (1999), "Intergroup behaviour in organizations: a field test of social identity theory”, Small Group Research, Vol. 30, pp. 361-82.

Jablin, G. and Putnam, L. (1987), Handbook of Organizational Communication: An Interdisciplinary Perspective, Sage, Newbury Park, CA.

Johns, G. (1994), "How often were you absent? A review of the use of self-reported absence data", Journal of Applied Psychology, Vol. 79, pp. 574-91.

Judge, T.A., Thoresen, C.J., Pucik, V. and Welbourne, T.M. (1999), "Managerial coping with organizational change: a dispositional perspective", Journal of Applied Psychology, Vol. 84, pp. 107-22.

Kanter, R.M., Stein, B.A. and Jick, T.D. (1992), The Challenge of Organizational Change: How Companies Experience It and Leaders Guide It, Free Press, New York, NY.

Karasek, R.A. (1979), "Job demands, job decision latitude and mental strain: implications for job redesign”, Administrative Science Quarterly, Vol. 24, pp. 285-307.

Katz, D. and Kahn, R.L. (1978), The Social Psychology of Organizations, 2nd ed., Wiley, New York, NY.

Kotter, J. (1995), "Leading change: why transformational efforts fail", Harvard Business Review, March-April, pp. 59-67.

Kouzes, J.M. and Posner, B.Z. (1993), Credibility: How Leaders Gain and Lose It, Why People Demand It, Jossey-Bass Publishers, San Francisco, CA.

Kramer, R.B. (1991), "Inter-group relations and organizational dilemmas: the role of categorisation processes", Research in Organizational Behaviour, Vol. 13, pp. 191-228.

Larkin, T.J. and Larkin, S. (1994), Communicating Change: How to Win Employee Support for New Business Directions, McGraw Hill, New York, NY.

Lazarus, R.S. and Folkman, S. (1984), Stress, Appraisal and Coping, Springer Publishing Company, New York, NY. 
Lewis, L.K. (1999), "Disseminating information and soliciting input during planned organizational change: implementers' targets, sources and channels for communicating”, Management Communication Quarterly, Vol. 13, pp. 43-75.

McManus, S.E., Russell, J.E.A., Freeman, D.M. and Rohricht, M.T. (1995), "Factors related to employees' perceptions of organisational readiness for change", paper presented at the annual meeting of the Academy of Management, Vancouver, August.

Martin, A., Jones, E. and Callan, V. (2005), "The role of psychological climate in facilitating employee adjustment during organizational change", European Journal of Work and Organizational Psychology, Vol. 14, pp. 263-89.

Meyer, J.P., Allen, N.J. and Smith, C.A. (1993), "Commitment to organizations and occupations: extension and test of a three-component conceptualization", Journal of Applied Psychology, Vol. 78, pp. 538-51.

Michela, J.L. and Burke, W.W. (2000), "Organizational culture and climate in transformations for quality and innovation", in Ashkanasy, N., Widerom, C. and Peterson, M. (Eds), Handbook Of Organizational Culture And Climate, Sage, Thousand Oaks, CA.

Miles, E., W, ., Patrick, S.L. and King, W.C. Jr (1996), "Job level as a systematic variable in predicting the relationship between supervisory communication and job satisfaction", Journal of Occupational and Organizational Psychology, Vol. 69, pp. 277-92.

Mowday, R.T., Steers, R.M. and Porter, L.W. (1979), "The measurement of organizational commitment", Journal of Vocational Behaviour, Vol. 14, pp. 224-47.

O'Driscoll, M.P. and Randall, D.M. (1999), "Perceived organizational support, satisfaction with rewards, and employee job involvement and organizational commitment", Applied Psychology: An International Review, Vol. 48, pp. 197-209.

Olson, D.A. and Tetrick, L.E. (1988), "Organizational restructuring: the impact on role perceptions, work relationships, and satisfaction", Group and Organization Studies, Vol. 13, pp. 374-88.

Parker, C.P., Baltes, B.B., Young, S.A., Huff, J.W., Altmann, R.A., Lacost, H.A. and Roberts, J.E. (2003), "Relationships between psychological climate perceptions and work outcomes: a meta-analytic review", Journal of Organizational Behaviour, Vol. 24, pp. 389-416.

Payne, R.L. (2000), "Climate and culture: how close can they get?", in Ashkanasy, N.M., Wilderom, C.P.M. and Peterson, M.F. (Eds), Handbook of Organizational Culture \& Climate, Sage Publications, Thousand Oaks, CA, pp. xvii-xxx.

Parker, P.A. and Kulik, J.A. (1995), "Burnout, self and supervisor-related job performance and absenteeism among nurses", Journal of Behavioural Medicine, Vol. 18, pp. 581-99.

Pettigrew, A. (2000), "Foreword", in Ashkanasy, N.M., Wilderom, C.P.M. and Peterson, M.F. (Eds), Handbook of Organisational Culture and Climate, Sage, Thousand Oaks, CA.

Rousseau, D.M. (1985), "Issues of level in organisational research: multi-level and cross-level perspectives", Research in Organisational Behaviour, Vol. 7, pp. 1-37.

Rowe, K.J. (2000), "Simultaneous estimation of interdependent effects among multilevel composite variables in psychosocial research: an annotated example of the application of multilevel structural equation modelling", in Duan, N. and Reise, S. (Eds), Multilevel Modeling: Methodological Advances, Issues and Applications, Lawrence Erlbaum \& Associates, Mahwah, NJ.

Sargent, L. (1995), "Public sector change: organizational stressors and strategic interventions", in Cotton, P. (Ed.), Psychological Health in the Workplace: Understanding and Managing Occupational Stress, The Australian Psychological Association, Carlton.

Schein, E.H. (1985), Organisational Culture and Leadership, Jossey-Bass, San Francisco, CA. 
JMP

21,2

162

Schein, E.H. (2000), "Sense and nonsense about culture and climate", in Ashkanasy, N., Widerom, C.P.M. and Peterson, M.F. (Eds), Handbook of Organizational Culture and Climate, Sage, Thousand Oaks, CA.

Schneider, B. (2000), "The psychological life of organizations”, in Ashkanasy, N.M., Widerom, C.P.M. and Peterson, M.F. (Eds), Handbook of Organizational Culture and Climate, Sage, Thousand Oaks, CA.

St Amour, D. (2001), "Successful organizational change: effective management of people and cultural issues", Canadian Manager, Summer, pp. 20-2.

Terry, D.J. and Callan, V.J. (1998), "Intergroup differentiation in response to an organizational merger", Group Dynamics: Theory, Research and Practice, Vol. 2, pp. 67-81.

Terry, D.J. and Jimmieson, N.L. (1999), "Work control and employee well-being: a decade in review", in Cooper, E.L. and Robertson, I.T. (Eds), International Review of Industrial and Organisational Psychology, 14, pp. 95-148.

Terry, D.J., Callan, V.J. and Sartori, G. (1996), "Employee adjustment to an organizational merger: stress, coping and intergroup differences”, Stress Medicine, Vol. 12, pp. 105-22.

Wanberg, C.R. and Banas, J.T. (2000), "Predictors and outcomes of openness to change in a reorganising workplace", Journal of Applied Psychology, Vol. 85, pp. 132-42.

Watson, B., Jones, E., Hobman, E., Bordia, P., Gallois, C. and Callan, V.J. (2005), Employees' Perceptions of Organizational Change: Impact of Organizational Level, (manuscript under review).

Winefield, A.H. (2000), "Stress in academe: some recent research findings", in Kenny, D.T., Carlson, J.G., McGuigan, F.J. and Sheppard, J.L. (Eds), Stress and Health: Research and Clinical Applications, Harwood Academic Publishers, Amsterdam.

Young, M. and Post, J.E. (1993), "Managing to communicate, communicating to manage: how leading companies communicate with employees", Organizational Dynamics, Vol. 22, pp. 31-43.

\section{Further reading}

Kline, R.B. (1998), Principles and Practices of Structural Equation Modelling, Guilford Press, London.

Lee, T.W., Mitchell, T.R., Wise, L. and Fireman, S. (1996), “An unfolding model of employee turnover”, Academy of Management Journal, Vol. 39, pp. 5-35.

Steers, R.M. and Mowday, R.T. (1981), "Employee turnover and post-decision accommodation processes", in Cummings, L.L. and Straw, B.M. (Eds), Research in Organizational Behaviour, 3rd ed., JAI Press, Greenwich, CT.

\section{Corresponding author}

Angela J. Martin can be contacted at: Angela.Martin@utas.edu.au

To purchase reprints of this article please e-mail: reprints@emeraldinsight.com Or visit our web site for further details: www.emeraldinsight.com/reprints 